Tucker, K. L., Martz, D. M., Curtin, L., \& Bazzini, D. G. (2007). Examining "Fat Talk" experimentally in a female dyad: How are women influenced by another woman's body presentation style? Body Image: An International Journal of Research, 4, 157 - 174. (ISSN: 1740-1445) Elsevier doi:10.1016/j.bodyim.2006.12.005

\title{
Examining "fat talk" experimentally in a female dyad: How are women influenced by another woman's body presentation style?
}

\author{
Katheryn L. Tucker, Denise M. Martz, Lisa A. Curtin, and Doris G. Bazzinia
}

\begin{abstract}
Fat talk, the verbal dissatisfaction that women express about their bodies, was studied in a female dyad whereby participants interacted with a female confederate who either self-derogated, self-accepted, or self-aggrandized. A 2 (participant body esteem: high vs. low) $\times 3$ (confederate style of body image presentation) design was used. Results revealed that participants' public disclosure of their body image varied according to confederate's style. Consistent with a reciprocity effect, participants disclosed the lowest public body image ratings in the self-derogate condition, with moderate ratings in the self-accept condition, and highest ratings in the self-aggrandize condition. Moreover, participants with low compared to high body esteem stated lower public body image. Participants' judgments of the confederates' likeability did not vary as a function of the confederate's body presentational style. Findings support the recursive nature of the social psychology of body image such that personal body image dissatisfaction is partially influenced by fat talk social norms.
\end{abstract}

\section{Introduction}

Public images of Western society's ideal female physique have changed across modern history. For example, Rubinstein and Caballero, 2000 S. Rubinstein and B. Caballero, Is Miss America an undernourished role model?, Journal of the American Medical 
Association 283 (12) (2000), p. 1569. Full Text via CrossRef | View Record in Scopus | Cited By in Scopus (26)Rubinstein and Caballero (2000) showed a steady decline in Miss America Pageant winners' body mass indexes (BMls) between 1922 and 1999. Sypeck et al. (2006) similarly documented male preferences for a leaner feminine physique across time by quantifying Playboy's centerfolds between 1979 and 1999, but noted that the trend for a decline in body sizes has appeared to stabilize more recently. This cultural ideal of thinness can impact how females perceive their own bodies. Prospective research has found that adolescent girls who wanted to look like thin female role models in the media developed more body image dissatisfaction than their peers (Field et al., 2001). Moreover, Groesz, Levine, and Murnen (2002), in a metaanalysis, found more body image disturbance among females who viewed thin media images, compared to those who viewed larger female models or inanimate objects.

Discussions about body image dissatisfaction often occur in female social groups, emerging as early as adolescence (Hope, 1980). Nichter and Vuckovic (1994) observed that Caucasian teens' conversations often center on negative self-statements about their bodies and they coined the term "fat talk" to describe these types of social exchanges. Indeed, although the construct of body image (i.e., emotions, perceptions and attitudes about body and appearance) was once thought to be a personal phenomenon, such discourses among women may be utilized as a means of "fitting in" to important social circles (Nichter \& Vuckovic, 1994). This suggests that beyond actual body image dissatisfaction, the normative discontent of body size in women may be fueled by pressure to derogate one's appearance. Thus, fat talk can be conceptualized as the extension of body image into the realm of interpersonal relations, particularly if women feel social pressure to express body discontent.

Illustrations of how audience type influences fat talk have been observed in both descriptive and experimental research in college-aged women. Britton, Martz, Bazzini, Curtin, and LeaShomb (2006) documented the social norm of body self-derogation for women. Using both forced-choice and open-ended options, male and female participants, who were presented with a scripted conversation involving four women expressing body dissatisfaction, identified body self-derogation as the most likely response for a target woman's contribution to the discussion. Hence, both male and female college students seem to recognize fat talk as normative.

Using an experimental design, Gapinski, Brownell, and LaFrance (2003) led female participants to believe they were completing a study about consumer preferences in 
seasonal clothing. While trying on either a swimsuit or a sweater (clothing style manipulation), female participants were exposed to a confederate in a neighboring dressing room who either expressed dissatisfaction with her body (fat talk) or expressed dissatisfaction with a non-body related topic. Participants who tried on the swimsuit reported greater frequency of body concern statements in an open-ended sentence completion task relative to participants in the sweater condition. Also, women who were exposed to fat talk while in a swimsuit experienced lower levels of negative emotions compared to women who were exposed to fat talk while in a sweater. The results suggest that women may feel comfortable with fat talk when experiencing concern about their own bodies, but may feel uncomfortable when exposed to fat talk in a less body-focused context.

Additionally, Stice, Maxfield, and Wells (2003) found that fat talk may be person/situation dependent. They studied the negative effects of social pressure to be thin by having women engage in a conversation with a thin, attractive confederate. The confederates had BMls of 18.2 and 18.6 placing them in the underweight or barely above underweight categories according to the Center for Disease Control and Prevention (2006) and making them leaner than most participants. Stice et al. (2003) found that women felt worse about their bodies after hearing the very thin confederate talk negatively about her body and describe her diet regimen than they did after hearing her talk about a neutral topic. Hence, this study suggested that a thin woman engaging in fat talk with a larger woman makes the latter feel bad. Moreover, Krones, Stice, Batres, and Orjada (2005) used a similar design whereby participants interacted with a confederate. The independent variable was the thinness of the confederate using a thin model with a BMI of 19 and a more normal weight confederate with a BMI of 24 . Independent raters found the thin versus normal BMI confederate to be considered more attractive. They found that interactions with the very thin woman increased body dissatisfaction among participants, but did not affect physiological arousal or negative affect compared to interactions with the normal weight female. They concluded that social comparison of normal weight women to thin women, both in the media and in an in vivo interaction, enhances body image dissatisfaction. Thus, fat talk in a female social context could prompt both social comparison and impression management.

The current study explored the influence of social context and perceptions of social attractiveness in relation to fat talk. It is possible that women speak negatively about their bodies because they feel pressured by a social norm (Britton et al., 2006). In fact, women may talk disparagingly about their bodies when other women self-derogate even 
when they are satisfied with their bodies. For instance, fat talk has been documented in female athletes who paradoxically report having a positive body image (Smith \& Ogle, 2006). In the present study, female participants reported how they felt about their bodies after a normal sized female confederate modeled one of three body presentational styles: self-derogation, self-acceptance, or self-aggrandizement. It was hypothesized that a woman's body presentational style would influence the way another woman subsequently rated her body in dyadic conversation.

In addition, it was proposed that a woman's perceived likeability would be affected by how she spoke about her body. A female confederate who followed the norm of body self-derogation was expected to be perceived as more likeable than a woman who did not follow the norm. Hence, this study examined if the social situation impacted participants' behavior and likeability of the other woman (confederate). It is also likely that personal characteristics have an impact on individuals' impression management of their body image in social circles and may impact their perception of others. Personal body esteem/dissatisfaction is likely the most relevant individual difference in a fat talk situation. Therefore, we examined the impact of participant body esteem (low vs. high) on their responses in a fat talk conversation. It was expected that those with higher body esteem would report the highest body ratings and those with lower body esteem would report the lowest body ratings during the experiment.

\section{Method}

\section{Participants}

Ninety-two female participants were recruited using the general psychology participant pool at a mid-sized, public, southeastern university. Four were eliminated because they knew the confederate, failed to report height and weight, or did not accurately complete the manipulation check, leaving 88 participants. On average, participants were 19.4 years of age $(\mathrm{SD}=2.8)$ with most identifying themselves as Caucasian $(88 \%, 7 \%$ African-American, 3\% Hispanic, 1\% Asian-American, 1\% Other). BMI scores ranged from 17.20 to 32.35 , with a mean score of $22.49(S D=3.36)$. Institutional Review Board (IRB) approval for the project was obtained January 18, 2005.

\section{Materials}

A self-designed demographic questionnaire was used to obtain the participant's age, race, and height and weight for BMI calculation. 


\section{Body esteem scale}

The body esteem scale (BES) is a measure of body satisfaction (Franzoi \& Shields, 1984). The BES consists of 35 items (e.g., "waist" and "body build") that are rated on a 5-point Likert scale from 5 = "have strong positive feelings" to 1 = "have strong negative feelings," with higher scores indicating higher body esteem and lower scores indicating greater body dissatisfaction. The internal consistency of the BES ranges between .78 and .87. The BES has moderate convergent validity when compared to other measures of esteem and body consciousness. In addition, the BES has good discriminate validity when compared to factors unrelated to body esteem (Franzoi \& Shields). The BES was used to determine participants' levels of body esteem prior to introducing the bodypresentational style manipulation. Using a median split at scores of 120, participants were divided into high $(>120)$ versus low $(\leq 120)$ BES creating an individual difference independent variable in this study. Cronbach's alpha revealed a reliability coefficient of .93 in the current study, suggesting it captured a unified construct.

\section{Filler task}

A 5-min word search filler task, described as an estimate of cognitive abilities, was used to distract participants after the BES.

\section{Disclosed interview body dissatisfaction}

Using a self-designed measure, the confederate and participant answered three questions and made ratings for each of the three question topics on a 10-point Likertscale during the interview. These ratings were presented on paper and out loud, in order to augment the social pressure in the dyad during the interview session. Possible scores ranged from 1 being "Very Bad" and 10 being "Very Good." The item of interest was the participant's response to the third question, "How do you feel about your body and how you look?" The confederate stated her ratings of " 1 " in the self-derogate condition, a " 6 " in the self-accept condition, and a " 10 " in the self-aggrandize condition. Participant ratings on this question solely were used as the disclosed interview body dissatisfaction score (DIBS), one of the two main dependent variables in this study.

\section{Social attractiveness index}


A variation of Rudman's (1998) social attractiveness index (SAI) was used, as the second dependent variable, to determine how much the participants liked the confederate after the experimental manipulation. The scale consisted of five items: "How much would you like to get to know the other participant better?, How much would you like to have the other participant as a friend?, How much do you want to participate in a joint task with the other participant?, Was the other participant likeable?, and Is the other participant popular?" The items were rated on a 7-point Likert scale ( 1 = "not at all" to 7 = "very much") and a sum was calculated to determine the participant's overall perception of the confederate's likeability. Lower scores reflected a low level of social attractiveness and higher scores reflected a high level of likeability. Cronbach's alpha on this sample revealed a reliability coefficient of .76. The SAI was used as a second dependent variable in this study to determine the participants perceived likeability of her partner (i.e., female confederate).

\section{Manipulation checks}

Manipulation checks were used to ensure that the participants attended to what the confederate said during the interviews by asking participants to recall the direction of confederates' responses for each of the three topics that they had discussed. Two participants were omitted due to their inability to accurately recall the confederate's body rating.

\section{Confederates and research assistants}

There were three female confederate/male research assistant (RA) teams that ran participants in balanced numbers across the three experimental conditions. All confederates were Caucasian females with BMls at 24.30, 25.50, and 22.10 placing them in the normal range (CDCP, 2006). In an effort for confederates to appear as typical college females, they dressed in blue jeans and t-shirts, using minimal make-up, during all experiment sessions.

\section{Design}

The study employed a $2 \times 3$ between-subjects factorial design. The first factor reflected the participant's initial level of high versus low body esteem. The style in which the female confederate talked about her body image was the second factor. The three body image presentation conditions were self-derogation $(n=31)$, self-acceptance $(n=30)$, or self-aggrandizement $(n=27)$. The two dependent variables were participants' body 
presentation ratings (DIBS) and their perception of the confederate's social attractiveness (SAI) that were disclosed subsequent to the confederate's responses about her body.

\section{Procedure}

Participants signed up individually for a research study titled, "Getting to Know Yourself and Others." The RA ran participants, one at a time, with her supposed female partner who was really the trained confederate. The RA ran the experiment by having the participant and her partner (confederate) first complete the consent form and BES and demographic questionnaires separately and in private, then jointly participate in a videotaped interview, 1 then separately and privately complete the dependent variable surveys, and then ostensibly complete a joint task together. The prospect of the joint task was used to increase the level of importance placed on the participant's opinion of her partner during the interview and was not actually conducted as part of the study.

Once the consent forms were collected from the participant and her partner, the RA explained that each person participating in the study had to be assigned the label $A$ or $B$. To determine who was $A$ and who was $B$, the RA asked the confederate to draw a slip of paper. The confederate always drew $A$ allowing her to respond to each of the interview topics first. The confederate left the room and the participant completed the initial questionnaires and the word search filler task in private. The RA returned with the confederate and instructed the participant and her partner (confederate) how to conduct the interview portion of the study, turned on the video cameras, and left the room during the interview. They were asked to provide open-ended responses and a numerical rating, on a scale of 1 to 10 , for three questions serving as conversational prompts: (1) "How do you feel about your classes?" (2) "How do you feel about your roommate?" and (3) "How do you feel about your body and how you look?" The confederate always went first and her responses to the first two questions were consistent across all experimental conditions. Her response to the third question varied according to the experimental condition.

In the self-derogate condition the confederate responded, "Well, I don't know. Hmmm, let me think. There are a lot of things I don't like about my body. I mean, I hate the way my stomach looks in a bathing suit... so I never wear a bikini. Oh, and I think my thighs are huge. I would say I am a 1." 
In the self-accept condition, the confederate stated, "Well, I don't know. Hmmm, let me think. I feel pretty comfortable with my body. I mean, I am about average and I feel ok about how I look. I would say I am a 6.

In the self-aggrandize condition, the confederate replied, "Well, I don't know. Hmmm, let me think. There are a lot of things I love about my body. I mean, I have a really cute stomach and I like showing it off in a bathing suit. Oh and I have great legs. I would say I am a 10."

Once the interview was finished, the RA escorted the confederate from the room so that the participant could complete the SAI and manipulation checks privately. After these were done, the RA debriefed the participant regarding the deception of the confederate's role in the study and explained there would not be a joint task.

\section{Results}

A one-way analysis of variance (ANOVA) showed no significant differences for BMI between participants assigned to the three conditions, $F(2,85)=0.05, p=.95$, . Similarly, ANOVA yielded no significant differences for participant body esteem scale scores across the conditions, $F(2,85)=1.19, p=.31$, , suggesting random assignment was achieved on these important pre-existing individual differences.

To examine whether participants' disclosed body satisfaction was impacted by BES Level and the confederate's style of body image presentation, DIBS ratings were submitted to a 2 (BES: high vs. low) $\times 3$ (body presentational style: self-derogate, selfaccept, and self-aggrandize) ANOVA. As Fig. 1 illustrates, results demonstrated significant main effects for BES level, $F(1,82)=31.38, p<.01$, and for condition, $F(2$, $82)=25.53, p<.01$. There was no significant interaction between BES level and condition, $F(2,82)=.66, p=.52$, . The main effect for $B E S$ revealed that on average, participants in the low BES group presented lower DIBS ratings $(M=5.10, S D=2.0)$ than participants in the high BES group $(M=7.07, S D=2.00)$. The main effect for condition indicated that there was a significant difference between DIBS ratings made by individuals in each of the body presentational style conditions. Post Hoc LSD indicated that individuals in the self-derogate condition made lower DIBS ratings $(M=$ 
4.50, $S D=2.10)$ than individuals in the self-accept condition $(M=6.00, S D=1.50)$, who in turn, made lower DIBS ratings than the individuals in the self-aggrandize condition (M $=7.56, \mathrm{SD}=1.80$, all ps <.02). It was also predicted that participants' initial body esteem and the body presentational style of the confederate would impact ratings of the confederate's likeability. Thus, a similar $2 \times 3$ ANOVA was used to examine the impact of BES level and confederate body presentational style on the SAI ratings. This analysis revealed no significant main effects for condition, $F(2,82)=0.57, p=.57$, or BES level, $F(1,82)=0.88, p=.35$, and no significant interaction between BES level and body presentational style for the SAI, $F(2,82)=0.49, p=.61$.

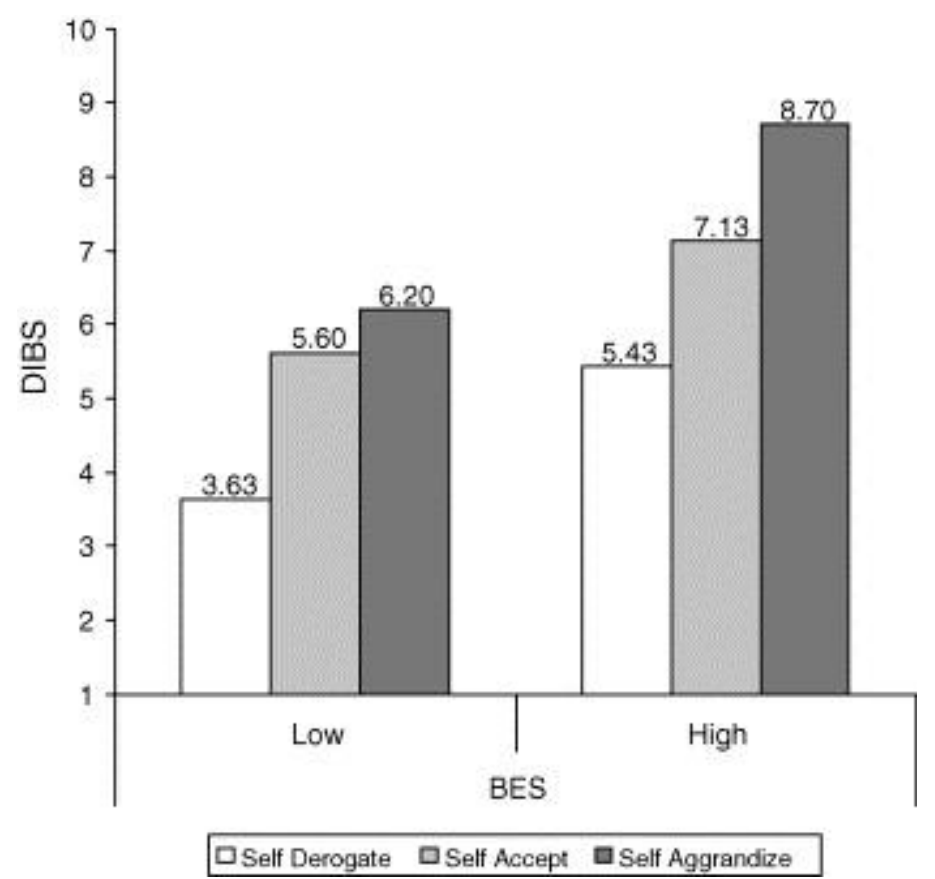

Fig. 1. Mean DIBS ratings as a function of confederate body image presentational style and participants' body esteem level.

\section{Discussion}

This was the first experimental investigation to assess whether the body presentational style of another woman would influence how a woman subsequently presents her own body image. Consistent with the hypothesis, when a woman spoke positively about her body, her partner in a public interview situation was more likely to publicly rate her own body favorably. If a woman spoke neutrally about her body, the other woman was more likely to present her own body in a relatively neutral manner. And finally, if a woman spoke negatively about her body, her partner was more likely to rate her own body 
unfavorably. Hence, participants tended to reciprocate the body image presentational style of the confederate. This finding is consistent with the self-disclosure literature that has documented a reciprocity norm among dyad members engaging in conversational interactions (e.g., DeForest \& Stone, 1980). However, and not surprisingly, pre-existing body esteem also influenced their disclosed ratings during the dyadic conversation. Therefore, the body image ratings of participants subsequent to the confederate's responses were influenced by both their individual differences in body esteem and the social context.

There are several possible explanations for this matching effect including conformity, impression management, and social comparison. First, participants may have been conforming to the confederate's responses under two types of social influencenormative and informational pressure (Aronson, 2004). Normative influence, most notably demonstrated in Asch's (1956) line judgment study, refers to social pressure based on a desire to be accepted by a group and avoid rejection. Thus, sometimes people conform as a method of impression management in order to be liked and accepted. Participants in the study may have wanted to be accepted by the confederate partner, and this motivation may have translated into body ratings that were similar to hers. Previous research has shown that women place a high value on same-sex, platonic relationships, and generally desire acceptance and inclusion in important social groups (Timmers, Fischer, \& Manstead, 1998). Thus, women may feel that expressing similar body satisfaction to that of another woman is a means by which social rejection can be avoided, and social acceptance can be gained.

By contrast, informational influence, as first exemplified by Sherif (1937) through the use of the autokinetic effect, occurs when a situation is ambiguous and an individual uses information provided by other people to formulate a response in a social situation. As social comparison theory (Festinger, 1954) would predict, in circumstances devoid of objective standards of reference, individuals will utilize other people in forming selfappraisals. The body ratings proclaimed by the confederates may therefore have been used as informational guides by the participants to help clarify the rating scale. It seems reasonable to argue that having a female discuss her body image serves as a prompt for social comparison given that the 10-point Likert scale that was used in this study was rather ambiguous in nature. In everyday life, people are rarely asked to make numerical ratings of how they feel about various self-attributes. Since each female confederate was of average size, her response may have created an appropriate standard for participants to then use in making their own rating. 
Although it appears conformity occurred, it was not possible to determine which type of social influence took place. Furthermore, if conformity pressure induced participants to modify their own body ratings, the meaning of these ratings is also unclear. For example, conformity induced through normative influence leads to public compliance, but not private acceptance of the behavior in question (Aronson, Wilson, \& Akert, 2005). Thus women would have reported ratings consistent with the confederate solely as a means of seeking acceptance. On the other hand, conformity induced by informational influence does lead to private acceptance or internalization of the behavior. In this case women would have provided ratings of how they actually felt about their bodies rather than utilizing ratings as a means of impression management. Both Stice et al. (2003) and Krones et al. (2005) demonstrated that interactions with a thin confederate can lessen private ratings of body satisfaction in controlled experiments. In the present research, we did not include an option for private ratings concomitant with the public ratings, so it is not possible to tease these apart. Again, future fat talk research should attempt to determine if women's body image esteem truly fluctuates depending on the social comparison of their audience versus if women deliberately impression manage their body image disclosures due to perceived social influence.

\section{Fat talk and likeability}

Britton et al. (2006) found that both women and men are aware of a fat talk norm for self-derogation among women about their bodies. This led to our prediction that when a female violated such a norm by disclosing positive feelings about her body, perceptions of her likeability would decrease relative to when she engaged in norm-consistent body derogation. Inconsistent with this prediction, the way a woman spoke about her body did not have an impact on her perceived likeability by her partner in the current study. It is, however, possible that the confederates' responses to the first two conversational prompts created the primacy effect of the participant's general impression of the confederate's likeability (Asch, 1946). In fact, the fat talk manipulation in this study was rather subtle compared to conversing with an underweight confederate who disclosed her body image dissatisfaction and discussed her diet and exercise regimen for 3-5 min (Stice et al., 2003) or Gapinksi et al.'s (2003) manipulation of the participants' clothing during neutral versus fat talk from a confederate. Perhaps the body talk manipulation used in this study was simply not strong enough to have a significant impact on confederate likeability and previous studies did not assess likeability. Moreover, although the norm for self-derogation is widely acknowledged, women may not experience overt social sanctions for going against the norm and saying positive things about their bodies, especially in a one-on-one dyad. Latane's (1981) social impact 
theory suggests that conformity to a social norm is a function of multiple factors including the number of members adhering to the norm. Future research could examine the level of conformity to body image presentational style by having more than one confederate expressing a unified view.

\section{Limitations}

Among the potential methodological shortcomings of the study was the one-item measure used to assess body presentational style. Albeit face valid, having a participant settle on a "public" number to represent body image fails to capture the true verbal and nonverbal aspects of fat talk. Further, it is possible that the external validity of the study was insufficient to generalize to other female interactions. Although great care was taken to make the experimental design as realistic as possible, particularly in regards to the interpersonal interaction between participant and confederate, there is arguably a lack of importance for the relationship between them. Fat talk is said to occur between females who know each other (Nichter \& Vuckovic, 1994) whereas females in this study were strangers. In an effort to make the relationship more salient, the participant and confederate were told at the beginning of the study that they would "work together to accomplish a joint task." No manipulation check was used prior to debriefing to determine whether or not the participants remembered they would be working to complete a task with the confederate. Even if participants did remember the joint task, they were not asked to report if this information influenced their behavior or their ratings of the confederate during the study, nor were they asked to rate the importance of the relationship.

Body presentational style did not influence ratings of the confederate's likeability, but in the real world of social interaction, it is rare for individuals to be directly asked to disclose social judgments of other people using a numerical value. The disparity between the formation of social judgments in the real world and the methods used to assess social judgments in this study renders the judgments somewhat artificial. Likeability of a woman in a real life fat-talk conversation with familiar females may result in harsher judgments based on body presentational style, especially about an outgroup member (Nichter \& Vuckovic, 1994). Moreover, the confederate was permitted to state her body image opinion first. This was perceived as "fair" considering that the confederate had drawn the right to go first. Perhaps her perceived likeability would have been different given the three body image presentational styles if they followed a context of female fat talk in a group. 
Participants in this study were drawn from a college-age participant pool, yet the seminal resources on fat talk and body derogation are based on information gathered from middle-school-aged females (Nichter \& Vuckovic, 1994). Developmental factors may influence social judgments related to body presentation. It is possible that as young women mature and graduate from middle and high school, the social ramifications of going against the norm of self-derogation lessen in severity. There is some evidence that as women age, they become less concerned with appearance and weight (Tiggemann, 2004). For example, Britton et al. (2006) found college students are aware of the fat talk norm, but reported they might not follow it themselves.

\section{Implications}

Despite methodological shortcomings, the present study provided an experimental test of situational and participant variables that influence body presentational style.

Therefore, this study represents a novel approach to experimentally examining how fat talk (or violation of such a norm) influences the way women present their bodies in the context of a social interaction. Future research could explore the effects of body presentational style and body esteem using familiar participants or comparing the context of a dyad versus a group. It would also be interesting to test whether women would present their bodies differently in front of men versus women. In fact, preliminary findings suggest that women believe that their body presentational style should be more positive when talking to a man than when talking to a woman if they want to be liked (Britton et al., 2006). An additional topic for future investigation is to assess whether men are similarly influenced by situational factors, such as body presentational style, and internal factors, such as body esteem, in the same way as women. Moreover, Nichter and Vukovic's (1994) seminal research on fat talk assessed middle school aged females' body image, at times, utilizing focus groups. The current research suggests that reports of body image subsequent to an initial female's fat talk may have been more of a reciprocity or conformity response, rather than a true public impression of her body esteem. Future research will want to clarify the many variables influencing the promulgation of fat talk.

In conclusion, fat talk is an interesting area of research as it merges research on personal body image dissatisfaction with social psychological influences of social comparison with peers and media with social psychological research on self-disclosure in a sociocultural context. We believe that many American women succumb to a vicious cycle of private/public body image dissatisfaction. If there is social pressure to fat talk and this is what females routinely hear in social circles, ordinary social interactions may 
reinforce their own personal body image discontent. Alternatively, there may be women who feel positively about their bodies who refrain from public disclosure for fear of social rejection, especially if these women fail to meet cultural expectations of thinness.

Perhaps future research on fat talk will facilitate feminist foundations for therapeutic interventions for individual body image disturbance or for political intervention related to fat talk portrayals in the media.

\section{Acknowledgments}

The authors wish to thank the following research assistants who were involved as confederates, experimenters, and assisted with data entry: Mary Senn, Luke Cichon, Katie Shepard, Adam Carhart, Carrie Eller, Alexandra Smucker, and Raphael Smith.

\section{References}

Aronson, 2004 E. Aronson, The social animal (9th ed.), Worth Publishers, New York (2004).

Aronson et al., 2005 E. Aronson, T.D. Wilson and R.M. Akert, Social psychology (5th ed.), Prentice Hall, New Jersey (2005).

Asch, 1946 S.E. Asch, Forming impressions of personality, Journal of Abnormal and Social Psychology 41 (1946), pp. 258-290.

Asch, 1956 Asch, S. E. (1956). Studies of independence and conformity: A minority of one against an unanimous majority. Psychological Monographs, 70 (9, Whole No. 416).

Britton et al., 2006 Britton, L., Martz, D. M., Bazzini, D., Curtin, L., \& LeaShomb, A. (2006). Fat talk and self-presentation of body image: Is there a social norm for women to self-degrade? Body Image: An International Journal of Research, 3, 247-254. 
CDCP, 2006 Center for Disease Control and Prevention (2006). BMI- Body Mass Index: Adult BMI Calculator: Results. Retrieved from world wide web on 12-5-06. (http://www.cdc.gov/nccdphp/dnpa/bmi/adult_BMl/english_bmi_calculator/results_under weight.htm?pounds=127\&inches $=70$ ).

DeForest and Stone, 1980 C. DeForest and G. Stone, Effects of sex and intimacy level on self-disclosure, Journal of Counseling Psychology 27 (1980), pp. 93-96.

Festinger, 1954 L. Festinger, A theory of social comparison processes, Human Relations 7 (1954), pp. 117-140.

Field et al., 2001 A.E. Field, C.A. Camargo, C.B. Taylor, C.S. Berkey, S.B. Roberts and G.A. Colditz, Peer, parent, and media influences on the development of weight concerns and frequent dieting among preadolescent and adolescent girls and boys, Pediatrics 107 (2001), pp. 54-60.

Franzoi and Shields, 1984 S.L. Franzoi and S.A. Shields, The Body Esteem Scale: Multidimensional structure and sex differences in a college population, Journal of Personality Assessment 48 (1984), pp. 173-178.

Gapinski et al., 2003 K.D. Gapinski, K.D. Brownell and M. LaFrance, Body objectification and "fat talk": Effects on emotion, motivation, and cognitive performance, Sex Roles: A Journal of Research 48 (2003), pp. 377-388.

Groesz et al., 2002 L.M. Groesz, M.P. Levine and S.K. Murnen, The effect of experimental presentation of thin media images on body satisfaction: A meta-analytic review, International Journal of Eating Disorders 31 (2002), pp. 1-16.

Hope, 1980 C. Hope, American beauty rituals. In: R.B. Browne, Editor, Rituals and ceremonies in popular culture, Bowling Green University Press, Bowling Green, $\mathrm{OH}$ (1980), pp. 226-237. 
Krones et al., 2005 P.G. Krones, E. Stice, C. Batres and K. Orjada, In vivo social comparison to a thin-ideal peer promotes body dissatisfaction: A randomized experiment, International Journal of Eating Disorders 38 (2005), pp. 134-142.

Latane, 1981 B. Latane, The social impact of majorities and minorities, Psychological Review 88 (1981), pp. 438-453.

Nichter and Vuckovic, 1994 M. Nichter and N. Vuckovic, Fat talk. In: N. Sault, Editor, Many mirrors: Body image and social relations, Rutgers University Press, New Brunswick, NJ (1994), pp. 109-131.

Rubinstein and Caballero, 2000 S. Rubinstein and B. Caballero, Is Miss America an undernourished role model?, Journal of the American Medical Association 283 (12) (2000), p. 1569.

Rudman, 1998 L.A. Rudman, Self-promotion as a risk factor for women: The costs and benefits of counterstereotypical impression management, Journal of Personality and Social Psychology 74 (1998), pp. 629-645.

Sherif, 1937 M. Sherif, An experimental approach to the study of attitudes, Sociometry 1 (1937), pp. 90-98.

Smith and Ogle, 2006 P.M. Smith and J.P. Ogle, Interactions among high school crosscountry runners and coaches: Creating a cultural context for athlete's embodied experiences, Family and Consumer Sciences 34 (2006), pp. 276-307. 
Stice et al., 2003 E. Stice, J. Maxfield and T. Wells, Adverse effects of social pressure to be thin on young women: An experimental investigation of the effects of "fat talk", International Journal of Eating Disorders 34 (2003), pp. 108-117.

Sypeck et al., 2006 M.F. Sypeck, J.J. Gray, S.F. Etu, A.H. Ahrens, J.E. Mosimann and C.V. Wiseman, Cultural representations of thinness in women, redux: Playboy magazine's depictions of beauty from 1979 to 1999, Body Image: An International Journal of Research 3 (2006), pp. 229-235.

Tiggemann, 2004 M. Tiggemann, Body image across the adult life span: Stability and change, Body Image 1 (2004), pp. 29-41.

Timmers et al., 1998 M. Timmers, A. Fischer and A. Manstead, Gender differences in motives for regulating emotions, Personality and Social Psychology Bulletin 24 (1998), pp. 974-985.

\section{Note}

1 The way women spoke about their bodies was recorded via videotape and will be used in a future study to determine whether the numerical ratings made by the participants were consistent with their open-ended verbal responses regarding their bodies. 